\title{
Synergistic Antioxidant Scavenging Activities of Grape Seed and Green Tea Extracts against Oxidative Stress
}

\author{
Hossam S. EL-BELTAGI ${ }^{1 *}$, Wael EL-DESOUKY², Rania S. YOUSEF ${ }^{1}$ \\ ${ }^{1}$ Cairo University, Faculty of Agriculture, Biochemistry Dept, P. Box 12613, Gamma St, Giza, Cairo, \\ Egypt; lbltg@yahoo.com (*correspondingauthor); nadaosa@yahoo.com \\ ${ }^{2}$ Atomic Energy Authority, Hot Laboratories Center, Cairo,Egypt; waeld5@hotmail.com
}

\begin{abstract}
Grape seed and green tea extracts are reported to produce antioxidant scavenging activities against free radical toxicity. This study aimed to investigate the hypothesis that a specific combination of these extracts presents a synergistic antioxidant scavenging activities. The extracts of grape seed, green tea and their mixtures were characterized by phytochemical studies and tested for phenolics and flavonoids. In vitro antioxidant activity for individual extract and its mixtures was determined by DPPH, hydroxyl and superoxide free radical scavenging methods. The amount of total phenolics varied among the different extracts and ranged from 43.74 to $67.68 \mathrm{mg}$ of gallic acid equivalents (GAE) / g dry weight, whereas total flavonoids content ranged from 4.25 to $11.66 \mathrm{mg}$ of quercetin equivalents (QU)/g dry weight. The present results suggest that both extracts reported a highly contents of total phenolic and flavonoids compounds, also the mixtures of these extracts can synergistically enhance antioxidant activity. Antioxidant potential from mixture 2 (grape seed extract $200 \mathrm{mg}$ : green tea extract $100 \mathrm{mg}$ ) was comparable to that of standard. HPLC results showed that the most abundant components in the mixture 2 extract were epigallocatechingallate while the lowest was the procyanidine.
\end{abstract}

Keywords: antioxidant activity, DPPH, grape seed extract, phenolics, synergism, tea extract

\section{Introduction}

Oxidative stress, induced by oxygen radicals, proved to be a major factor in various degenerative diseases, such as cancer, malignant diseases, diabetes and atherosclerosis (Muramatsu et al., 1995; Bandyopadhyay et al., 1997; Apel and Hirt, 2004). Antioxidant has been described as any substance that interferes with the response of any substance with oxygen (Poljsak et al., 2013). Moreover an antioxidant is any substance that hinders a free radical reaction (Rahman 2007). The presence of antioxidant systems protects the cell membrane against damage caused by free radicals. Enzymatic antioxidants include: superoxide dismutase, glutathione peroxidase and catalase and non-enzymatic antioxidants include: glutathione and vitamins systems. In general supplementation by antioxidants, like vitamins $\mathrm{A}, \mathrm{C}, \mathrm{E}$, cysteine and glutathione is known to decrease free-radical damage caused by radiation treatment (Deger $e t$ al., 2003; El-Beltagi et al., 2011). There are numerous interests in natural antioxidants extracted from medicinal plants, vegetables and fruits, which might help to prevent oxidative damage (Yilmaz and Toledo, 2004). Of the naturally polyphenolic compounds, catechins and their polymers, procyanidins have obtained a large interest due to their antioxidant properties that can perform scavenging action on free radicals superoxide, hydroxyl, and 1,1-diphenyl-2picrylhydrazyl (DPPH), metal chelating properties, reduction of hydroperoxide formation and their effects on cell signaling pathways and gene expression (Jacob et al., 2008). Catechins and procyanidins are found mostly in green tea and red wine, respectively (Perumalla and Hettiarachchy, 2011). Important health advantages were related with these compounds including the prevention and the treatment of several cardiovascular diseases and cancers (Jeong and Kong, 2004). Grape seed extract (GSE) is a by-product derived from the grape seeds (Vitis vinifera) that is extracted, dried and purified to produce a polyphenolic compound rich extract (Lau and King, 2003). Grape seeds composition and properties have been extensively investigated, and reported to have helpful effects on human health such as the decreasing of low-density lipoprotein (Teissedre et al., 1996; Vigna et al., 2003), reduction of cardiovascular diseases and cancer (Waterhouse, 1994). Several groups have studied GSE for antimicrobial, anticancerogenic, antihypertensive, antihyperglycemic, cardiovascular and hypercolostrolemic properties (Clifton, 2004; Peng et al., 2005; Jung et al., 2006; Broker et al., 2006). The seed extracts of Vitis vinifera have been showed to have antimicrobial and antioxidant properties (Jayaprakasha $e t$ 
368

al., 2001), decrease the hazard of chronic disease by protecting against ROS mediated damage (Caillet et al., 2006) and inhibit the incidence of stroke due to its radical scavenging action and inhibition of lipid peroxidation (Uchida et al., 1995).

It is believed that humans have consumed tea (Camellia sinensis, family Theaceae) for more than 5000 years and currently it is still one of the most usually used beverages worldwide, second only to water (Graham, 1992; Demeule et al., 2002). Green tea is made from leaves of Camellia sinensis that have undergone minimal oxidation during processing. Recently green tea become the main topic of medical studies suggesting that regular tea drinkers may have a reduce risk of promoting heart disease and certain types of cancer (Zaveri, 2006; Yamada and Watanabe, 2007). Green tea has been considered a drug since old times and has been recommended for headaches, body aches and pains, digestion, depression, detoxification, as an energizer and, in general, to prolong life (Cabrera et al., 2006; Neturi et al., 2014). The chemical composition of green tea extract is complex, consisting of polyphenols (catechins and flavanoids), alkaloids, volatile oils, polysaccharides, amino acids, lipids, vitamin $\mathrm{C}$, minerals and other compounds (Karori et al., 2007; Afify et al., 2011). Among these, the largest component present in green tea leaves is carbohydrates (including cellulosic fiber) and the simplest compounds are catechins, a group of flavanoids called flavan-3ols (Yilmaz, 2006). Catechins and other polyphenols act as antioxidants in vitro by isolating metal ions and by scavenging ROS and nitrogen species (Dufresne and Farnworth, 2002; Frei and Higdon 2003; Wiseman et al., 1997). The aim of the present study was to investigate the synergistic antioxidant scavenging activities of grape seed and green tea extracts and their mixtures using different systems and can be used for decreasing the harmful effects of free radicals and may be valuable as natural nutritional health supplement.

\section{Materials and Methods}

\section{Chemicals}

Folin-Ciocalteu reagent, 2, 2-diphenyl-1- picrylhydrazyl (DPPH), sodium carbonate, aluminum chloride and chemical HPLC-grade standards (purity $\geq 95 \%$ ) of gallic acid, (-) catechin gallate, (-)-gallo catechins, (-)-catechin, (-)epigallocatechin, (-)-epicatechin, procyanidin B1, procyanidin B2, procyanidine $\mathrm{C} 1,(-)$-epigallocatechingallate, (-)gallocatechin gallate, procyanidine $\mathrm{C} 2$ and (-)epicatechingallate were purchased from Sigma-Aldrich (St. Louis, MO, USA). Synthetic antioxidants such as butylated hydroxytoluene (BHT) and butylated hydroxyanisole (BHA) were obtained from Merck (Darmstadt, Germany). Acetonitrile and phosphoric acid were of HPLC grade, while the other reagents used in the experiments were of analytical grade.

\section{Grape seed extract (GSE)}

Ripened grapes (Vitis vinifera $\mathrm{L}$ ) of the most popular grape cultivars grown in Egypt, 'Roumy Ahmer' (red grape cultivar), were bought from the local market. Following manual separation of the seeds from whole berries, grape seeds (GS) were dried in oven at $50^{\circ} \mathrm{C}$ for 3 days and later were grounded to fine powder by grinder. One hundred $\mathrm{g}$ of GS powder was extracted with $500 \mathrm{ml}$ of ethanol $50 \%$ and left for one day at room temperature. The extract was filtered through Büchner funnel followed by ethanol removal using vacuum rotary evaporator at $40^{\circ} \mathrm{C}$. The residue gained was dissolved in water and kept at $4{ }^{\circ} \mathrm{C}$ until further use (Ahn et al., 2002). The selection of ethanol $50 \%$ as the organic solvent was based on the fact that ethanol when mixed with water facilitates the solubility of the bioactive compounds compared to pure water (Nawaz et al., 2006).

\section{Green Tea Extract (GTE)}

Green tea leaves were bought from the local market. Ethanol extract was prepared according to Gramza et al. (2006). Extracts were prepared by triplicate 24 hours maceration of grinded $100 \mathrm{~g}$ tea leaves with $250 \mathrm{ml}$ ethanol 95\% at ambient conditions. Collected extracts were filtered and centrifuged (7000 rpm, $15 \mathrm{~min}$ ), ethanol was evaporated on rotary evaporator. The powdered ethanol extract was kept frozen $\left(-18^{\circ} \mathrm{C}\right)$ until further use.

\section{Mixture preparation}

After extraction of both GSE and GTE they were mixed together to obtain two different mixtures with ratio of 1:1 (100 $\mathrm{mg}$ GSE, $100 \mathrm{mg}$ GTE) and 2:1 (200 mg GSE, $100 \mathrm{mg}$ GTE), respectively. The mixtures were kept frozen at $-20{ }^{\circ} \mathrm{C}$ until further use.

\section{Determination of total soluble phenolic contents}

The total soluble phenolic contents of GSE, GTE and each mixture solution were determined using Folin-Ciocalteu reagent (Erkan et al., 2008). One $\mathrm{ml}$ of GSE, GTE and each mixture solution $(0.1 \mathrm{mg} / \mathrm{ml})$ was mixed with $7.5 \mathrm{ml}$ of FolinCiocalteu reagent which was diluted with distilled water. After keeping it at room temperature for $5 \mathrm{~min}, 7.5 \mathrm{ml}$ of $60 \mathrm{mg} / \mathrm{ml}$ of $\mathrm{Na}_{2} \mathrm{CO}_{3}$ solution were added. After 2 hrs at room temperature the absorbance was measured at $725 \mathrm{~nm}$ against blank using Genway spectrophotometer. Gallic acid was used as a standard and expressed as mg gallic acid equivalents per gram of grape seed dry matter (mg GAE/g DW). The samples were analyzed in triplicates.

\section{Determination of total flavonoids contents}

Ethanolic extracts of GSE, GTE and each mixture solution $(250 \mathrm{ml})$ were mixed with $1.25 \mathrm{ml}$ of distilled $\mathrm{H}_{2} \mathrm{O}$ and $75 \mathrm{ml}$ of a $5 \% \mathrm{NaNO}_{2}$ solution. After $5 \mathrm{~min}, 150 \mathrm{ml}$ of a $10 \%$ $\mathrm{AlCl}_{3} \cdot \mathrm{H}_{2} \mathrm{O}$ solution was added and filtered for $6 \mathrm{~min}$. About $500 \mathrm{ml}$ of $1 \mathrm{M} \mathrm{NaOH}$ and $275 \mathrm{ml}$ of distilled $\mathrm{H}_{2} \mathrm{O}$ were added to the mixture, mixed well and the intensity of color was measured at $510 \mathrm{~nm}$. The content of total flavonoid concentration was calculated using quercetin $(\mathrm{QU})$ as a standard (Jia et al., 1999). The results were expressed as mg of quercetin equivalents per gram of grape seed dry matter $(\mathrm{mg}$ QU/g DW). The samples were analyzed in triplicates.

\section{HPLC analysis of GTE and GSE mixture extracts}

Sample solution of GTE and GSE mixture $200 \mu \mathrm{g} / \mathrm{ml}$ was analyzed by LC/DAD/MS HPLC, Agilent (serious 1100 quartary pump). LC/DAD/MS HPLC conditions was as follows, column type; Reversed phase Zorbax Eclipse Plus $\mathrm{C}_{18}$ (Agilent, $3.5 \mu \mathrm{m}$ ); column dimensions, $4.6 \times 100 \mathrm{~mm}$; column oven temperature, $35^{\circ} \mathrm{C}$; mobile phases, (A) water / phosphoric acid 1000, 1 (v/v), (B) acetonitrile / phosphoric 
acid 1000, $1(\mathrm{v} / \mathrm{v})$; a gradient program, (B) $0 \%(0 \mathrm{~min})=15 \%$, $(20 \mathrm{~min})=30 \%,(25 \mathrm{~min})=100 \%,(45-61 \mathrm{~min})=0(62-77$ min); detector type, UV and Mass detector; monitor wavelengths, 210 and $280 \mathrm{~nm}$; injection volume, $10 \mu \mathrm{l}$. Phosphoric acid has an absorbance at $210 \mathrm{~nm}$, and that was the reason for correcting the HPLC chromatograms by subtracting the base line. All extracts were prepared in triplicate and each extract was analyzed in triplicate.

\section{DPPH scavenging activity}

The antioxidant activity of plant ethanol extracts was measured based on the radical scavenging ability in reaction with a stable DPPH free radical according to Blois (2002). Briefly, $0.1 \mathrm{mM}$ of DPPH in ethanol was prepared and $1 \mathrm{ml}$ of this solution was added to $3 \mathrm{ml}$ ethanolic extracts $(10,50,100$, $150 \mu \mathrm{g} / \mathrm{ml})$. The mixture was shaken and allowed to stand at room temperature for $30 \mathrm{~min}$ in the dark. Then the absorbance was measured at $517 \mathrm{~nm}$. The radical scavenging activities BHT and BHA were determined also as positive controls. Minimum absorbance of the reaction mixture indicated maximum free radical scavenging activity. Purple colored stable free radicals were reduced to yellow colored diphenylpicrylhydrazine when antioxidant was taken. The corresponding blank readings were taken and the capability to scavenge DPPH radical was calculated using the following equation,

$\mathrm{DPPH}^{\circ}$ scavenging activity $(\%)=\left[\left(A_{0}-A_{1} / A_{0}\right)\right] \times 100$,

where,

$\mathrm{A}_{0}=$ The absorbance of control reaction (containing reagents except the test compounds).

$\mathrm{A}_{1}=$ The absorbance in presence of the tested extracts.

\section{Hydroxyl radical scavenging activity}

The hydroxyl radical scavenging activity was measured according to the methods of Singh et al. (2002). About $0.1 \mathrm{ml}$ of ethanolic extracts $(10,50,100,150 \mu \mathrm{g} / \mathrm{ml})$ were added in different test tubes. About $1.0 \mathrm{ml}$ of iron-EDTA solution ( $0.1 \%$ ferrous ammonium sulfate and $0.26 \%$ EDTA), $0.5 \mathrm{ml}$ of dimethylsulfoxid (DMSO) $(0.85 \% \mathrm{v} / \mathrm{v}$ in $0.1 \mathrm{M}$ Phosphate buffer, $\mathrm{pH} 7.4$ ) were taken to these tubes, and the reaction was started by adding $0.5 \mathrm{ml}$ ascorbic acid $0.22 \%$. Test tubes were capped tightly and heated on a water bath at $80-90^{\circ} \mathrm{C}$ for 15 min. The reaction was inhibited by addition $1 \mathrm{ml}$ of ice cold TCA (17.5\%w/v). About $3 \mathrm{ml}$ of Nash reagent (75 g ammonium acetate, $3 \mathrm{ml}$ glacial acetic acid, and $2 \mathrm{ml}$ acetyl acetone were mixed and increased to $1 \mathrm{~L}$ with distilled water was added to all tubes and left at room temperature for $15 \mathrm{~min}$ for the color development. The intensity of yellow color formed was determined spectrophotometrically at $412 \mathrm{~nm}$ against the reagent control. The radical scavenging activities of BHT and BHA were also measured as positive controls. The percentage of hydroxyl radical scavenging activity was calculated by using the formula,

Hydroxyl radical activity $(\%)=1-\left[A_{1} / A_{0}\right] \times 100$,

where,

$\mathrm{A}_{1}=$ absorbance of tested extracts.

$\mathrm{A}_{0}=$ absorbance of control (containing all reagents except the test compounds).

Superoxide anion radical scavenging activity

Superoxide radicals were produced by the method of
Giannopolites and Ries (1977) modified by Siddhurajua et al. (2000). All the solutions were prepared in $0.05 \mathrm{M}$ phosphate buffer ( $\mathrm{pH}$ 7.8). The photo induced reactions were completed in aluminium foil-lined box with two 30W fluorescent lamps. The space between the reaction solution and the lamp was regulated until the intensity of illumination reached about 4000 lux. A $30 \mu \mathrm{L}$ aliquot of various concentrations (10, 50, $100,150 \mu \mathrm{g} / \mathrm{ml}$ ) of extracts was mixed with $3 \mathrm{ml}$ of reaction buffer solution (1.3 mm riboflavin, $13 \mathrm{mM}$ methionine, $63 \mu \mathrm{M}$ nitro blue tetrazolium and $100 \mu \mathrm{M}$ EDTA, $\mathrm{pH} 7.8)$. The reaction solution was illuminated for $15 \mathrm{~min}$ at $25^{\circ} \mathrm{C}$. The reaction mixture, without sample extract, was used as a control. The radical scavenging activities of BHT and BHA were also determined as positive controls. The scavenging activity was calculated as follows:

Superoxide anion radical scavenging activity $(\%)=1-\left[A_{l} /\right.$ $\left.A_{0}\right] \times 100$,

where,

$\mathrm{A}_{1}=$ absorbance of tested extracts,

$\mathrm{A}_{0}=$ absorbance of control (containing all reagents except the test compounds).

\section{Statistical analysis}

Each statistical analysis was carried out with SPSS10 version software. Mean and standard error were descriptive measures of quantitative data using the analysis of variance test (ANOVA) for independent samples and $\mathrm{p}$-values $<0.05$ were considered significant. All the measurements were done in triplicate.

\section{Results and Discussion}

\section{Total phenolic and total flavonoids content of extracts}

Total phenolic and total flavonoids content of grape seed and green tea extracts individually and the prepared mixtures were examined (Table 1). The amount of total phenolics varied among the different extracts and ranged from 43.74 to 67.68 $\mathrm{mg}$ GAE/g dry weight. Total flavonoids content ranged from 4.25 to $11.66 \mathrm{mg}$ QU /g dry weight. The highest phenolic and total flavonoids contents were significantly recorded in mixture 2 (200 mg GSE: $100 \mathrm{mg}$ GTE) extract. In contrast, the lowest contents of total phenolic and total flavonoids were noticed in GTE extract. This result indicated that mixture 2 extract presented a large amount of total phenolic and flavonoids than grape seed and green tea extracts individually and the prepared mixture 1. It can be establish the order of all the extracts with highest value of total phenolic and total flavonoids content as follows: mixture 2 (200 mg GSE: $100 \mathrm{mg}$ GTE) > mixture 1 (100 mg GSE: $100 \mathrm{mg} \mathrm{GTE})>$ GSE > GTE.

\section{HPLC phenolic composition of the mixture 2 (200 mg GSE: $100 \mathrm{mg} G T E$ ) \\ Polyphenol composition of mixture 2 was determined by} LC/DAD/MS HPLC analysis and the results are shown in Fig. 1. The separation of the phenolic compounds in mixture 2 was achieved within $60 \mathrm{~min}$. Identified Compounds (arranged according to their appearance in the attached chromatogram) are as follows in Table 2. The obtained results reported the presence of highly quantities of natural antioxidant compounds in mixture 2 (200 mg GSE: $100 \mathrm{mg}$ GTE) with a highly relatively percentages when the Epigallocatechingallate 


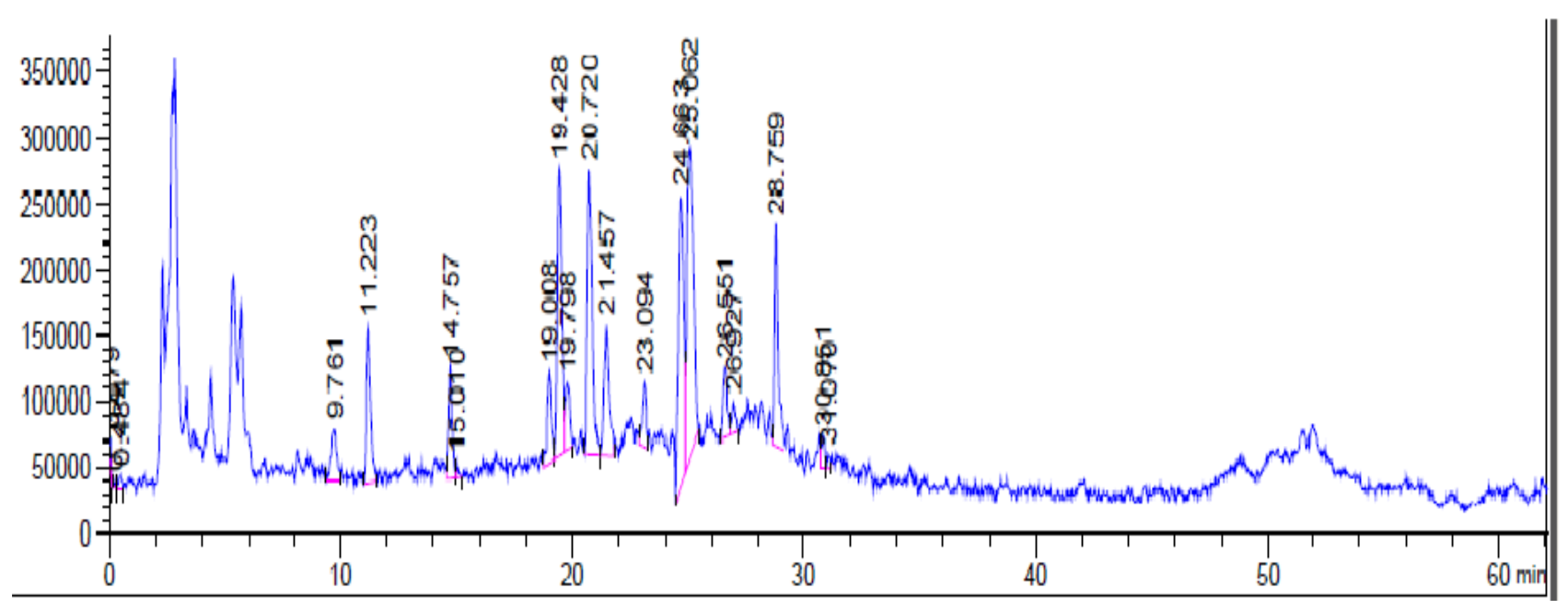

Fig. 1. MS-HPLC chromatogram of mixture 2 (200 mg GSE: 100 mg GTE)

Table 1. Total phenolic and total flavonoids contents of the ethanolic extracts of grape seed, green tea and prepared mixtures

\begin{tabular}{|c|c|c|}
\hline Extracts & Total phenolic* & Total flavonoids** \\
\hline GSE & $46.44 \pm 0.35^{c}$ & $4.98 \pm 0.08^{c}$ \\
\hline GTE & $43.74 \pm 0.26^{\mathrm{d}}$ & $4.25 \pm 0.12^{\mathrm{d}}$ \\
\hline Mixture 1 & $59.34 \pm 0.40^{b}$ & $10.58 \pm 0.20^{b}$ \\
\hline Mixture 2 & $67.68 \pm 0.52^{a}$ & $11.66 \pm 0.23^{a}$ \\
\hline LSD 0.05 & 1.12 & 0.45 \\
\hline \multicolumn{3}{|c|}{$\begin{array}{l}\text { Data with different superscript letters in the same column were differed } \\
\text { significantly }(\mathrm{P} \leq 0.05){ }^{*} \text { Mean of triplicate determinations } \pm \mathrm{SE} \text { expressed as } \mathrm{mg} \\
\text { GAE acid equivalent } / \mathrm{g} \text { dry weight, }{ }^{* *} \text { Mean of triplicate determinations } \pm \mathrm{SE} \\
\text { expressed as mg QU equivalent } / \mathrm{g} \text { dry weight. GSE: grape seed extract, GTE: } \\
\text { green tea extract, Mixture } 1(100 \mathrm{mg} \text { GSE: } 100 \mathrm{mg} \text { GTE), Mixture } 2 \text { (200 mg } \\
\text { GSE: } 100 \mathrm{mg} \text { GTE) }\end{array}$} \\
\hline
\end{tabular}

(EGCG) 19.12\%, Epicatechin (EC) 14.22\%, Catechin reported 13.38\%, Epigallocatechin (EGC) 11.85\%, (-) Epicatechingallate (ECG) 7.30\%, Procyanidine C1 6.61\%, (-) Catechin Gallate (CG) 6.23\%, Procyanidine B1 3.7\%, (-) Gallo Catechin (GC) 3.61\%, (-) Gallocatechin gallate (GCG) 2.91\%, Procyanidine B2 2.81\% and Gallic Acid (GA) 2.61\%. The major compound in GSE and GTE mixture 2 are catechins such as EGCG followed by EC, Catechin, EGC, ECG, while the lowest compounds was the procyanidine. The obtained results are in accordance with the results of previous studies which revealed that, the main compounds in GSE and GTE are catechins and the content of proanthocyanidins are at least 10 times lowers than catechins (Gramza et al., 2005; Mandić et al., 2009; Wang et al., 2014). Polyphenolic compounds (mainly flavanoids) present in green tea and grape seed extracts have demonstrated potential antioxidant properties due to their redox potential; that enable them to act in various forms such as hydrogen donors, reducing agents, resultant oxygen quenchers, and chelating metal ions in numerous food applications (Gramza et al., 2006). The active hydroxyl groups present in the molecular structure of polyphenols are the active components of the green tea and grape seed extracts that can interact with the free radicals to inhibit lipid oxidation (Mitsumoto et al., 2005). Furthermore, green tea and grape seed polyphenols can exhibit scavenging activity against free radicals (Rice-Evans et al., 1997), peroxynitrite, superoxide
Table 2. Relative percentage of identified compounds represented in mixtures 2 (200 mg GSE: 100 mg GTE) via MS-HPLC

\begin{tabular}{ccc}
\hline $\begin{array}{c}\text { Retention } \\
\text { time }\end{array}$ & Compound & $\begin{array}{c}\text { Relative } \\
\text { percentage } \\
(\%)\end{array}$ \\
\hline 9.761 & Gallic Acid (GA) & 2.61 \\
11.223 & $(-)$ Catechin Gallate (CG) & 6.24 \\
14.75 & $(-)$ Gallo Catechin (GC) & 3.61 \\
19.00 & Procyanidine B1 & 3.71 \\
19.42 & $(-)$ Epigallocatechin (EGC) & 11.85 \\
19.798 & Procyanidine B2 & 2.81 \\
20.72 & (-) Catechin & 13.38 \\
21.45 & Procyanidine C1 & 6.61 \\
23.09 & Procyanidine B2 & 2.41 \\
\hline 24.663 & $(-)$ Epicatechin (EC) & 14.22 \\
25.06 & $(-)$ Epigallocatechingallate & 19.12 \\
& (EGCG) & 2.91 \\
26.551 & (-) Gallocatechin gallate & (GCG) \\
\hline 26.927 & Procyanidine C2 & 1.12 \\
\hline 28.759 & $(-)$ Epicatechingallate (ECG) & 7.30 \\
\hline
\end{tabular}

radicals, chelate copper and iron, preventing metal catalyzed free radical formation (Lin and Liang, 2000). Flavonoids from plant extracts end the radical chain reactions that occur during the oxidation of triglycerides in food systems (fats, emulsions and oils) and thus can act as free radical scavengers (Turkoglu et al., 2007; Mohamed et al., 2010). Presence of O-dihydroxy and O-hydroxyketo groups and $\mathrm{C}_{2}-\mathrm{C}_{3}$ double bonds are linked to the scavenging activity of different catechin molecules (Rice-Evans et al., 1997). Thus, EGCG has the most scavenging activity of free radicals followed by ECG, EC, and EGC as the antioxidant functions of the plant catechins depends on the structure, position and number of hydroxyl groups (Hu et al., 2001). Proanthocyanidins in the form of monomeric phenolic compounds, such as catechin, 
epicatechin and epicatechin-3-O-gallate, and in dimeric, trimeric and tetrameric procyanidin forms are rich in GSE. These can combine with gallic acid to form gallate esters and ultimately glycosides (Negro et al., 2003; Weber et al., 2007). The red color and astringency taste of the GSE can be attributed to polyphenol rich compounds especially proanthocyanidins which may affect the color and sensory characteristics of the product when used at higher concentrations (Monteleone et al., 2004; Weber et al., 2007).

\section{DPPH Radical Scavenging Activity}

The free radical scavenging activity of different concentrations $(10,50,100$ and $150 \mathrm{\mu g} / \mathrm{ml})$ from extracts of grape seed and green tea extracts individually and the prepared mixtures were determined by the DPPH method compared with $\mathrm{BHA}$ and $\mathrm{BHT}$ as standard and the results are shown in Fig. 2. Antioxidant molecules can quench DPPH free radicals and convert them to a colourless product, resulting in a decrease in absorbance at $517 \mathrm{~nm}$. All the studied extracts showed significantly high radical scavenging activity ranging from 52.87 to 59.04 at $10 \mu \mathrm{g} / \mathrm{ml}$, from 63.82 to 77.13 at 50 $\mu \mathrm{g} / \mathrm{ml}$, from 78.04 to 85.83 at $100 \mu \mathrm{g} / \mathrm{ml}$ and from 85.0 to 90.0 at $150 \mathrm{\mu g} / \mathrm{ml}$. The highest radical scavenging activity in all concentrations was in mixture 2 (200 mg GSE: $100 \mathrm{mg}$ GTE) compared to synthetic food antioxidants BHA, BHT. The results obtained indicated that, higher percentage of DPPH scavenging activity in case of mixture 2 may be attributed to the higher total phenolic and flavonoids contents present in mixture 2. In several studies significant correlation was found between DPPH scavenging activity and the total phenolic content of a number of grape seed and tea extracts from different cultivars (Bakkalbasi et al., 2005). The obtained data from Fig. 2 showed that, all the treatments reported a highly DPPH-Free radical scavenging activity against in vitro oxidative stress specially in $150 \mathrm{\mu g} / \mathrm{ml}$, but the highly quantity of natural antioxidant phenolic compounds and total flavonoids in grape seed extract reflect the highest antioxidant activity in mixture 2 (200 mg GSE: $100 \mathrm{mg}$ GTE) in compare to mixture 1 and GSE, GTE separately. Like other polyphenolic compounds, catechins and procyanidins have an antioxidant property,

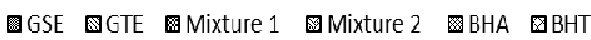

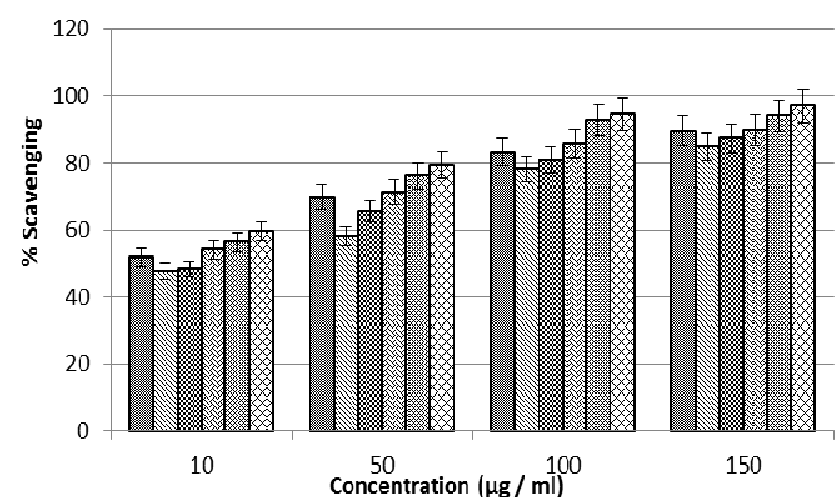

Fig. 2. DPPH radical scavenging activity (\%) of different extracts concentrations of grape seed, green tea, prepared mixtures, BHA and BHT. GSE: grape seed extract, GTE: green tea extract, Mixture 1 (100 mg GSE: 100 mg GTE), Mixture 2 (200 mg GSE: 100 mg GTE), BHA: Butylated hydroxyanisole, BHT: Butylated hydroxytoluene which may partially account for their useful role in heart diseases. Catechins and procyanidins have been shown to scavenge several forms of free radicals such as 2,2-diphenyl-1picrylhydrazyl (DPPH) radical, singlet oxygen $\left({ }^{1} \mathrm{O}_{2}\right)$, superoxide anion $\left(\mathrm{O}_{2}{ }^{-}\right)$, nitricoxide $\left(\mathrm{NO}^{\circ}\right)$, hydroxy $\left(\mathrm{OH}^{\circ}\right)$ and alkyl peroxyl radicals due to their redox potential; that enable them to act in various forms such as hydrogen donors, reducing agents, nascent oxygen quenchers, and chelating metal ions in numerous food applications (Sichel et al., 1991; SantosBuelga and Scalbert, 2000; Sang et al., 2003; Gramza et al., 2006).

\section{Hydroxyl radical scavenging activity}

The hydroxyl radical is an extremely reactive free radical created in biological systems and capable of damaging almost every molecule found in living cells and it is considered to be lipid peroxidation process, removing hydrogen atoms from unsaturated fatty acids (Kappus, 1991). The obtained data from Fig. 3 showed that, all concentrations (10, 50, 100 and $150 \mu \mathrm{g} / \mathrm{ml}$ ) of different extracts reported a highly significantly hydroxyl radical scavenging activity against in vitro oxidative stress but the highly quantity of natural antioxidant phenolic compounds and total flavonoids in grape seed extract reflect the highest antioxidant activity in mixture 2(200 mg GSE: 100 $\mathrm{mg}$ GTE). The antioxidant potential of GSE is twenty and fifty fold greater than those of vitamins $\mathrm{E}$ and $\mathrm{C}$ respectively (Shi $e t$ al., 2003). Mixture 2 extract at the higher concentration 150 $\mathrm{\mu g} / \mathrm{ml}$ has the hydroxyl radical activity of $90 \%$ followed by 89.64, 87.54 and $85 \%$ of GSE, mixture 1 and GTE extracts respectively, compared with standards such as BHT with 97.06\% and BHA with $94.02 \%$ scavenging activity. These results indicated that strong $\mathrm{OH}^{*}$ scavenging activities of mixture 2 extract were closely related to their high levels of phenolic compounds and due to the scavenging of the radical by hydrogen donation. This is similar to the observation of several others researchers who have reported a dose dependent activity in other foods such as sesame, sorghum, pomegranate peel and seeds, grapes pomace and seeds (Chang et al., 2002; Singh et al., 2002; Zhang et al., 2011; Afify et al., 2012; Abdel-Rahim et al., 2013).

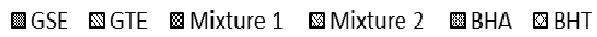

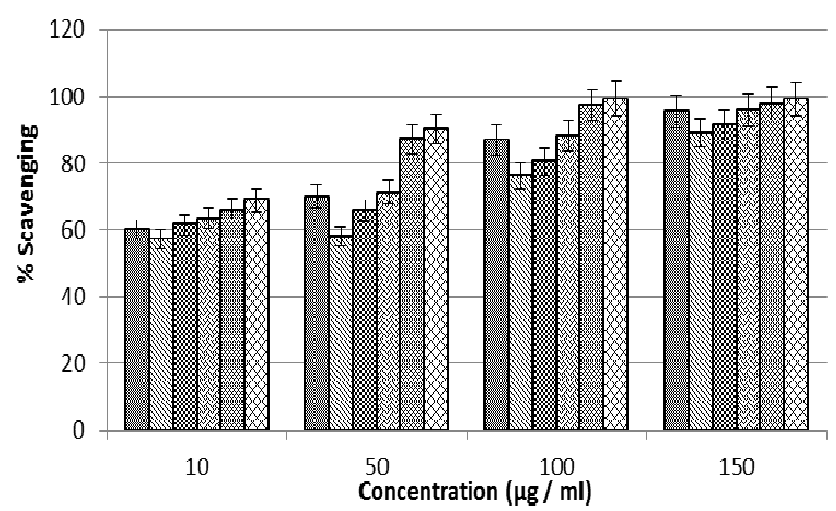

Fig. 3. Hydroxyl radical scavenging activity (\%) of different extracts concentrations of grape seed, green tea, prepared mixtures, BHA and BHT. GSE: grape seed extract, GTE: green tea extract, Mixture 1 (100 mg GSE: 100 mg GTE), Mixture 2 (200 mg GSE: 100 mg GTE), BHA: Butylated hydroxyanisole, BHT: Butylated hydroxytoluene 
372

\section{Superoxide radical scavenging activity}

Superoxide radical scavenging activity data revealed that the scavenging activity tendencies were similar to those obtained for DPPH and hydroxyl radical scavenging activity. Thus, the mixture 2 (200 mg GSE: $100 \mathrm{mg}$ GTE) extract had a significantly higher scavenging activity value at all concentrations than other extracts (Fig. 4). In addition, all the treatments of GSE individually gave a significant increase in superoxide scavenging activity comparing with GTE individually due to the highly quantity of natural antioxidant phenolic compounds and total flavonoids in grape seed extract that reflect the highest antioxidant activity in mixture 2 in comparison with mixture 1 . The scavenging activity of mixture 2, GSE, mixture 1, GTE extracts at higher concentration 150 $\mu \mathrm{g} / \mathrm{ml}$ were: $95.98,95.45,90.51$ and $89.16 \%$ respectively, compared with standard antioxidants BHA and BHT (97.76\%, 99.12\% respectively). Superoxide anion plays an important role in plant tissues and is involved in the formation of other cell-damaging free radicals (Bloknina et al., 2003). Superoxide has been observed to directly start lipid peroxidation. It has also been reported that antioxidant properties of some flavonoids are effective mainly through scavenging of superoxide anion radical (Yen and Duh, 1994). Superoxide anions derived from dissolved oxygen by the phenazine methosulphate (PMS) - nicotinamide adenine dinucleotide hydride (NADH) system will decrease nitroblue tetrazolium (NBT) in this system. In this method, superoxide anion reduces the yellow dye $\left(\mathrm{NBT}^{2+}\right)$ to produce the blue formazan, which is measured spectrophotometrically. Antioxidants are able to inhibit the blue NBT formation (Parejo et al., 2002). The decrease of absorbance in presence of antioxidants evidences consumption of superoxide anion in the reaction mixture. The increasing order of the percentage superoxide scavenging activities was mixture $2>\mathrm{GSE}>$ mixture $1>$ GTE. These effects may be attributed to the antioxidant activity of the studied extracts, indicating the phenolic and flavonoids presence in the extracts for governing the $\mathrm{O}_{2}{ }^{-}$ scavenging activities. The antioxidant properties of procyanidins from grape seeds have been shown to suppress superoxide anion and lipid peroxidation and to reduce or delay

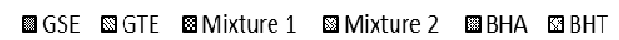

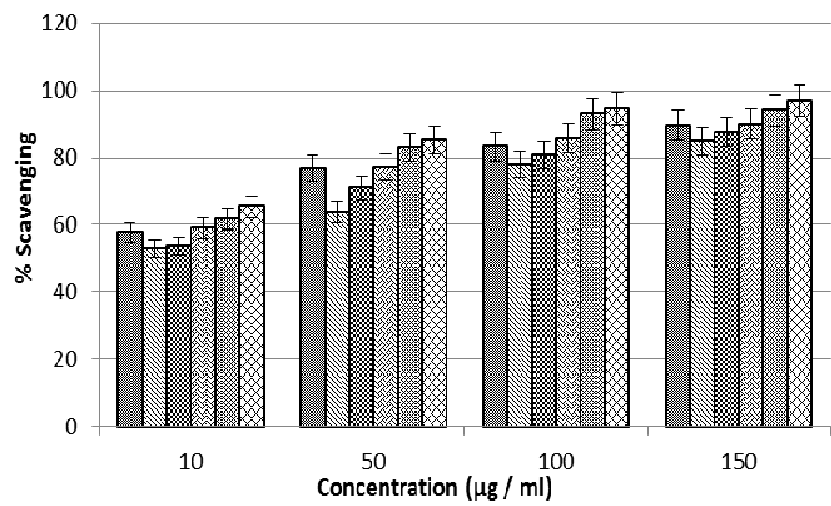

Fig. 4. Superoxide radical scavenging activity (\%) of different extracts concentrations of grape seed, green tea, prepared mixtures, BHA and BHT. GSE: grape seed extract, GTE: green tea extract, Mixture 1 (100 mg GSE: $100 \mathrm{mg}$ GTE), Mixture 2 (200 mg GSE: 100 mg GTE), BHA: Butylated hydroxyanisole, BHT: Butylated hydroxytoluene the formation of conjugated dienes during all stages of lipid peroxidation including induction, propagation, and breakdown (Maffei-Facino et al., 1996). In fact, phenolics are one of the major classes of natural antioxidants found in plants that remove such free radicals. Polyphenols are able to neutralize free radicals, scavenge singlet and triplet oxygen, and to break down peroxides. It is clearly shown that the number of phenolic-OH groups present in the structure of an antioxidant molecule isn't always the only factor determining its antioxidant activity. Positions of phenolic-OH groups, presence of other functional groups in the whole molecule, such as double bonds and their conjugation to $(-\mathrm{OH})$ groups and ketonic groups, also play important roles in antioxidant activities (Rice-Evans et al., 1996; El Gengaihi et al., 2015).

\section{Conclusions}

The mixture of GSE and GTE (200 mg: $100 \mathrm{mg}$ ) was found to be an effective antioxidant more than GSE and GTE separately. Based on the achieved results, it can be concluded that GSE and GTE mixture have the potency to act as a powerful antioxidant and can be used for decreasing the harmful effects of free radicals or reactive oxygen species (ROS) and lipid peroxidation thereby may be valuable as natural nutritional health supplement. In addition, potential use of these natural plant extracts could offer the food processing industries an alternative solution to synthetic chemical antioxidants.

\section{Acknowledgements}

The work was supported by the Faculty of Agriculture, Cairo University and Hot Laboratories Center, Atomic Energy Authority.

\section{References}

Abdel-Rahim EA, El-Beltagi HS, Romela RM (2013). White Bean seeds and Pomegranate peel and fruit seeds as hypercholesterolemic and hypolipidemic agents in albino rats. Grasasy Aceites 64:50-58.

Apel K, Hirt H (2004). Reactive oxygen species, Metabolism, Oxidative Stress, and Signal Transduction. Annual Review of Plant Biology 55:373-399.

Afify AMR, Shalaby EA, El-Beltagi HS (2011). Antioxidant activity of aqueous extracts of different caffeine products. Notulae Botanicae Horti AgrobotaniciCluj-Napoca39(2):117-123.

Afify AMR, El-Beltagi HS, Abd El-Salam SM, Omran AA (2012). Biochemical changes in phenols, flavonoids, tannins, vitamin E, Pcarotene and antioxidant activity during soaking of three white sorghum varieties. Asian Pacific Journal of Tropical Biomedicine 2:203-209

Ahn H, Jeona T, Lee J, Hwang S, Lim Y, Park D (2002). Antioxidative activity of persimmon and grape seed extract, in vitro and in vivo. Nutrition Research 22:1265-1273.

Bakkalbasi E, Yemis O, Artik N (2005). Major flavan-3-ol composition and antioxidant activity of seeds from different grape cultivars grown in Turkey. European Food Research and Technology 221:792-797.

Bandyopadhyay G, Standaert ML, Zhao L, Yu B, Avignon A, Galloway L, Karnam P, Moscat J, Farese RV (1997). Activation of protein kinase C 
(alpha, beta, and zeta) by insulin in 3T3/L1 cells. Transfection studies suggest a role for protein kinase C-zeta in glucose transport. Journal of Biological Chemistry 272:2551-2558.

Blois MS (2002). Antioxidant determinations by the use of a stable free radical. Nature 26:1199-1200.

Bloknina O, Virolainen E, Fagerstedt KV (2003). Antioxidants, oxidative damage and oxygen deprivation stress, a review. Annals of Botany 91:179-194.

Broker S, Martin S, Pearson A, Bagchi D, Earl J, Gothard L, Hall E, Porter L, Yarnold J (2006). Double-blind, placebo-controlled, randomised phase II trial of IH636 grape seed proanthocyanidin extract (GSPE) in patients with radiation-induced breast induration. Radiotherapy and Oncology79:45-51.

Cabrera C, Artacho R, Gimenez R (2006). Beneficial effects of green tea - a review.Journal of American College of Nutrition 25:79-99.

Caillet S, Salmieri S, Lacroix M (2006). Evaluation of free radical-scavenging properties of commercial grape phenol extracts by a fast colorimetric method. Food Chemistry 95:1-8.

Chang C, Yang MH, Wen HM, Chern JC (2002). Estimation of total flavonoid content in vegetables by two complementary colorimetric methods. Journal of Food and Drug Analysis 10:178-182.

Clifton PM (2004). Effect of grape seed extract and quercetin on cardiovascular and endothelial parameters in high-risk subjects. Journal of Biomedicine and Biotechnology 5:272-278.

Deger Y, Dede S, Belge A, Mert N, Kahraman T, Alkan M (2003). Effect of $\mathrm{x}$-rays radiation on lipid peroxidation and antioxidant systems in rabbits treated with antioxidant compound. Biological Trace Element Research 94:149-156.

Demeule M, Michaud-Levesque J, Annabi B, Gingras D, Boivin D, Jodoin J, Lamy S, Bertrand Y, Beliveau R (2002). Green tea catechins as novel antitumor and antiangiogenic compounds. Current Medicinal Chemistry-Anti-Cancer Agents 2:441-463.

Dufresne C, Farnworth E (2000). Tea, Kombucha, and health, a review. Food Research International 33:409-421.

El-Beltagi HS, Ahmed OK, El-Desouky W (2011). Effect of low doses $\gamma$ irradiation on oxidative stress and secondary metabolites production of rosemary (Rosmarinus officinalis L.) callus culture. Radiation Physics and Chemistry 80:968-976.

El Gengaihi S, Aboul Ella FM, Ibrahim AY, Abou Baker DH (2015). Antioxidant Activities of Selected Grape Wastes from Egypt. Human Journals 4:212-229.

Erkan N, Ayranci G, Ayranci E (2008). Antioxidant activities of rosemary (Rosmarinus officinalis L.) extract, blackseed (Nigella sativa L.) essential oil, carnosic acid, rosmarinic acid and sesamol. Food Chemistry 110:7682.

Frei B, Higdon JV (2003). Antioxidant activity of tea polyphenols in vivo, evidence from animal studies. Journal of Nutrition 133:3275S-3284S.

Giannopolites CN, Ries SK (1977). Superoxide dismutase. I. Occurrence in higher plants. Plant Physiology 59:309-314.

Graham HN (1992). Green tea composition, consumption, and polyphenol chemistry. Preventive Medicine 21:334350.

Gramza A, Korczak1 J, Amarowicz R (2005). Tea polyphenols - their antioxidant properties and biological activity - a review. Polish Journal of Food and Nutrition Sciences 14:219-235.
Gramza A, Khokhar S, Yoko S, Gliszczynska-Swiglo A, Hes M, Korczak J (2006). Antioxidant activity of tea extracts in lipids and correlation with polyphenol content. European Journal of Lipid Science and Technology 108:351-362.

Hu XF, Yang XQ, Liu KX (2001). Structure-activity relationship of tea polyphenols. Beijing, China, Beijing Science Press 60-69.

Jacob JK, Hakimuddin F, Paliyath G, Fisher H (2008). Antioxidant and antiproliferative activity of polyphenols in novel high-polyphenol grape lines. Food Research International 41:419-428.

Jayaprakasha GK, Singh RP, Sakariah KK (2001). Antioxidant activity of grape seed (Vitis vinifera) extracts on peroxidation models in vitro. Food Chemistry 73:285-290.

Jeong WS, Kong ANT (2004). Biological properties of monomeric and polymeric catechins, green tea catechins and procyanidins. Pharmaceutical Biology 42:8493.

Jia Q,Hong MF, MinterDP (1999). A novel iridoid from Picrorbiza kurroa. Journal of Natural Products 62:901-903.

Jung KJ, Wallig MA, Singletary KW (2006). Purple grape juice inhibits 7 , 12-dimethylbenz[a] anthracene (DMBA)-induced rat mammary tumorigenesis and in vivo DMBA-DNA adduct formation. Cancer Letters 233:279-288.

Kappus H (1991). In: Aruoma O, Halliwell B (Eds). Lipidperoxidation; Mechanism and biological relevance in the book free radicals and food additives. London, Taylor and Francis Ltd pp 59-75.

Karori SM, Wachira FN, Wanyoko JK, Ngure RM (2007). Antioxidant capacity of different types of tea products. African Journal of Biotechnology 6:2287-2296.

Lau DW, King AJ (2003). Pre and post-mortem use of grape seed extract in dark poultry meat to inhibit development of thiobarbituric acid reactive substances. Journal of Agricultural and Food Chemistry 51:1602-1607.

Lin J, Liang Y (2000). Cancer chemoprevention by tea polyphenols. Proceedings of the National Science Council, Republic of China B 24(1):1-13.

Maffei-Facino R, Carini M, Aldini G, Berti F, Rossoni G, Bombardelli E, Morazzoni P (1996). Procyanidines from Vitis vinifera seeds protect rabbit heart from ischemia/reperfusion injury, antioxidant intervention and/or iron and copper sequestering ability. Planta Medica 62(6):495502.

Mandić AI, Djilas SM, Čanadanović-Brunet JM, Ćetković GS, Vulić JJ (2009). Antioxidant activity of white grape seed extracts on Dpph radicals. Acta Periodica Technologica 40:53-61.

Mitsumoto M, O'Grady MN, KerryJP, Buckley DJ (2005). Addition of tea catechins and vitamin $\mathrm{C}$ on sensory evaluation, colour and lipid stability during chilled storage in cooked or raw beef and chicken patties. Meat Science 69:773-779.

Mohamed AA, Khalil AA, El-Beltagi HES (2010). Antioxidant and antimicrobial properties of kaff maryam (Anastatica hierochuntica) and doumpalm (Hyphaene thebaica). Grasasy Aceites 61(1):67-75.

MonteleoneE, Condelli N, Dinnella C, Bertuccioli M (2004). Prediction of perceived astringency induced by phenolic compounds. Food Quality and Preference 15:761-69.

Muramatsum H, Kogawa K, Tanaka M, Okumura K, Koike K, Kuga T (1995). Superoxide dismutase in SAS human tongue carcinoma cell line 
374

is a factor defining invasiveness and cell motility. Cancer Research 55:6210-6214.

Nawaz H,ShiJ, Mittal G, Kakuda Y (2006). Extraction of polyphenols from grape seeds and concentration by ultrafilterarion. Separation and Purification Technology 48:176-181.

Neturi RS, Srinivas R, Vikram Simha B, Sree SY, Chandra Shekar T, Siva Kumar P (2014). Effects of green tea on Streptococcus mutans counts-a randomised control trail. Journal of Clinical and Diagnostic Research 8:128-130.

Negro C, Tommasi L, Miceli A (2003). Phenolic compounds and antioxidant activity from red grape marc extracts. Bioresource Technology 87:41-44.

Parejo I, Viladomat F, Bastida J (2002). Comparison between the radical scavenging activity and antioxidant activity of six distilled and nondistilled Mediterranean herbs and aromatic plants. Journal of Agricultural and Food Chemistry 50:6882-6890.

Peng N, Clark JT, Prasain J, Kim H, White CR, Wyss JM (2005). Antihypertensive and cognitive effects of grape polyphenols in estrogendepleted, female, spontaneously hypertensive rats. American Journal of Physiology. Regulatory, Integrative and Comparative Physiology 289:771-775.

PerumallaAVS, Hettiarachchy NS (2011). Green tea and grape seed extracts potential applications in food safety and quality. Food Research International 44:827-839.

Poljsak B, Suput D, and Milisav I (2013). Achieving the balance between ROS and antioxidants: when to use the synthetic antioxidants. Oxidative Medicine and Cellular Longevity 2013:956792.

Rahman K (2007). Studies on free radicals, antioxidants, and cofactors. Clinical Interventions in Aging2:219-236.

Rice-Evans CA, Miller NJ, Paganaga G (1996). Structure-antioxidant activity relationships of flavonoids and phenolic acids. Free Radical Biology and Medicine 20:933-956.

Rice-Evans CA, Miller NG, Paganaga G (1997). Antioxidant properties of phenolic compounds. Trends in Plant Sciences 2:152-159.

Sang S, Tian S, Wang H, Stark RE, Rosen RT, Yang CS, Ho CT (2003). Chemical studies of the antioxidant mechanism of tea catechins, Radical reaction products of epicatechin with peroxyl radicals. Bioorganic \& Medicinal Chemistry 11:3371-3378.

Santos-Buelga C, Scalber A (2000). Proanthocyanidins and tannin-like compounds-nature, occurrence, dietary intake and effects on nutrition and health. The Journal of the Science of Food and Agriculture 80:1094-1117.

Sharma G, Tyagi AK, Singh RP, Chan DC, Agarwal R (2004). Synergistic anti-cancer effects of grape seed extract and conventional cytotoxic agent doxorubicin against human breast carcinoma cells. Breast Cancer Research and Treatment 85:1-12.

Shi J, Yu J, Pohorly JE, Kakuda Y (2003). Polyphenolics in grape seedsbiochemistry and functionality. Journal of Medicinal Food 6:291-299.

Sichel G, Corsaro C, Scalia M, Di Biliom AJ, Bonomo RP (1991). In vitro scavenger activity of some flavonoids and melanins against $\mathrm{O}_{2}$. Free Radical Biology and Medicine 11:1-8.
Siddhurajua P, Mohanb PS, Beckera K (2002). Studies on the antioxidant activity of Indian Laburnum (Cassia fistula L.), a preliminary assessment of crude extracts from stem bark, leaves, flowers and fruit pulp. Food Chemistry 79:61-67.

Singh RP, Murthy CKN, Jayaprakash GK (2002). Studies on the antioxidant activity of pomegranate (Punica granatum) peel and seed extracts using in vitro models. Journal of Agricultural and Food Chemistry 50:81-86.

Teissedre PL, Frankel EN, Waterhouse AL, Pele GH, German JB (1996). Inhibition of in-vitro human LDL oxidation by phenolic antioxidants from grapes and wines. Journal of the Science of Food and Agriculture 70:55-61.

Turkoglu A, Duru ME, Mercan N, Kivrak I, Gezer K (2007). Antioxidant and antimicrobial activities of Laetiporus sulphureus (Bull.) Murill. Food Chemistry 101:267-273.

Uchida S, Ozaki M, Akashi T, Yamashita K, Niwa M, Taniyama K (1995). Effects of (-)-epigallocatechin-3-O-gallate (green tea tannin) on the life span of stroke-prone spontaneously hypertensive rats. Clinical and Experimental Pharmacology and Physiology 22:302-303.

Vigna GB, Constantini F, Aldini G, Carini M, Catapano A, Schena F, Tangerini A, Zanca R, Bombardelli E, Morazzoni P, Mezzetti A, Fellin R, Maffei-Facino R(2003). Effect of a standardized grape seed extract on low-density lipoprotein susceptibility to oxidation in heavy smokers. Metabolism 52:1250-1257.

Wang L, Santos E, Schenk D, Rabago-Smith M (2014). Kinetics and mechanistic studies on the reaction between cytochrome $\mathrm{c}$ and tea catechins. Antioxidants 3:559-568.

Waterhouse AL (1994). Wine antioxidants may reduce heart disease and cancer. Presentation of American Chemical Society, Washington DC.

Weber HA, Hodges AE, Guthrie JR, O'Brien BM, Robaugh D, Clark AP, Harris RK, Algaier JW, Smith CS (2007). Comparison of proanthocyanidins in commercial antioxidants: Grape seed and pine bark extracts. Journal of Agricultural and Food Chemistry 55:148-156.

Wiseman SA, Balentine DA, Frei B (1997). Antioxidants in tea. Critical Reviews in Food Science and Nutrition 37:705-708.

Yamada H, Watanabe H (2007). Tea polyphenols in preventing cardiovascular diseases. Cardiovascular Research 73:439-440.

Yen G, Duh P (1994). Scavenging effect of methanolic extract of peanut hulls on free radical and active oxygen species. Journal of Agricultural and Food Chemistry 42:629-632.

Yilmaz Y, Toledo R (2004). Health aspects of functional grape seed constituents. Trends in Food Science \& Technology 15:422-433.

Yilmaz Y (2006). Novel uses of catechins in foods. Trends in Food Science \& Technology 17:6471.

Zaveri NT (2006). Green tea and its polyphenolic catechins, medicinal uses in cancer and noncancer applications. Life Science 78:2073-2080.

Zhang A, Fang Y, Wang H, Li H, Zhang Z (2011). Free-radical scavenging properties and reducing power of grape cane extracts from 11 selected grape cultivars widely grown in China. Molecules 16:10104-10122. 